\title{
A comparative study regarding secondary school students' satisfaction degree regarding the physical education class in Romanian and in Turkey
}

\author{
Teodora-Mihaela Iconomescu ${ }^{1, *}$, Veronica Mindrescu $^{2}$, and Ileana-Monica Popovici ${ }^{3}$ \\ 1،'Dunarea de Jos'" University, Domneasca Street, 47, Galati, 800008, Romania \\ ${ }^{2}$ Transilvania University, Eroilor Street, 29, Brasov, 500036, Romania \\ 3، Alexandru Ioan Cuza"' University, Carol I Street, 11, Iasi 700506, Romania
}

\begin{abstract}
In order for physical education classes in school to achieve their goals in the training and development of pupils, they must participate with pleasure, convinced that physical exercise helps them maintain an optimal state of health, a harmonious physical and personality development. For these reasons, it is important to know how students appreciate the physical education classes, how attractive they are to them, and what are their views on how to improve teaching techniques. The survey was conducted during school year 2015-2016, in November for the school from Turkey, on a number of 100 respondents and in March, for the schools from Romania, on a number of 94 respondents. The self-designed questionnaire represents the most widely used method in quantitative sociological research. The self-designed questionnaire contained a total of 10 questions that followed: In the first 4 questions, it was followed the pupils' opinion regarding the number of physical education classes in the school curriculum, the degree of satisfaction with the physical education classes in school, and the benefits that physical activity is believed to have. Questions 5-7 aimed at the rewards or sanctions received in the physical education class and the conflicts that may arise in the relationship between teacher and student. In both countries, physical education and sport require knowledge of all aspects associated with physical exercise, students' willingness to exercise and practise a sport, the desire to engage in physical exercises and their awareness of the influence that physical education has on their health.
\end{abstract}

Keywords: pupils, PE classes, attitudes

\section{Introduction}

Physical education has a predominant formative character, in a way that it prepares the subjects for life, and for the necessities of everyday life.

Physical education, being a part of the general education in schools of all degrees, has to fulfill the general needs of the youth: maintaining an optimal state of health, fostering harmonious physical development, improving the overall motor capacity, developing the

* Corresponding author: ticonomescu@ugal.ro, the present paper is the result of the equal contribution of all authors. 
habit of practicing independent and systematic exercise, and the harmonious development of the subject's personality.

The discipline of "physical education" is provided in the curriculum for gymnasium education as a compulsory discipline in the schools in Romania and Turkey, the two countries in which the research was conducted.

The cultural and historical traditions are the most common reasons for choosing physical activities in schools. These are also reflected in the teaching of traditional dances and games, rooted in the culture of society. In gymnasium, the minimum recommended time for physical education is generally $6-8 \%$ of the total teaching time in most countries, while in Turkey the proportion is only 3-4\% [9].

Improving the physical education lesson can attract the student to the enjoyment of movement so that he can continue to do physical activity, whether we are talking about outdoor games or various other sports, all being a good opportunity to socialize and to develop new and long-lasting friendships.

The educational value of practicing physical exercise depends decisively on how well students are attracted to the physical education class at school, and the degree of satisfaction of the lesson taught. The teacher will pursue didactic strategies designed to make physical education more effective, to educate students that physical education is a personal necessity for everyone, along with other daily necessities $[4,6]$.

The concept of Physical Education is a modern notion, being a new stage of gymnastics, as it was called in ancient times. Initially, Physical Education had some limited purposes, being regarded only as a mean of recreation after a more intense intellectual activity. Over time, Physical Education has diversified its content and gained deeper meanings.

Although for a long time Physical Education has been understood only as an action primarily aimed at fostering the right and harmonious growth of the youth body, endowing and developing the motor skills, abilities and habits, and preparing the youth for life, afterwards, after it expanded its scope and content of action, Physical Education became a permanent program that was extended to all categories of people.

As stated by Nicola [8], "the ideal of our education consider it to be an indispensable component that is contributing to the formation of human personality". Physical Education plays a decisive role by contributing to the harmonious development of personality and ensuring a functional balance between its components, particularly the physical and mental component.

In conclusion, Physical Education is not only aimed at achieving a limited and intrinsic purpose of physical development, but on the contrary it is a component of a system, and together with all the other components it acts on the integral development of personality, stimulating and strengthening its psychophysical qualities [1, 7]. Physical Education seeks to achieve a harmonious and psychophysical balance through the continuous development of biological and psychological elements.

Physical Education also reflects itself on the other aspects of education. By its specificity it contributes to the functional development of the nervous system, thus ensuring the favourable conditions for the successful development of the intellectual activity. The beauty of the movements and the rhythm of the deployment give many aesthetic valences.

\section{Research methods}

\subsection{Procedure}

The research was conducted in the school year 2015-2016, in November for the Turkish school and in March for the schools in Romania. The working method in the research 
undertaken was the data collection procedure using the self-designed questionnaire addressed to samples of pupils from the 7 th and 8 th grades from both research countries. As a tool for collecting the data used in the research, the researcher used the paper questionnaire handed directly to the subjects. For both countries, the self-designed questionnaire was given in the mother tongue and explained to the respondents how to complete and all the additional information they requested. The self-designed questionnaire represents the most widely used method in quantitative sociological research. The selfdesigned questionnaire contained a total of 10 questions that followed: In the first 4 questions, it was followed the pupils' opinion regarding the number of physical education classes in the school curriculum, the degree of satisfaction with the physical education classes in school, and the benefits that physical activity is believed to have. Questions 5-7 aimed at the rewards or sanctions received in the physical education class and the conflicts that may arise in the relationship between teacher and student. The last three questions addressed the student-teacher relationship and the conflicting nature that may arise.

\subsection{The subjects}

In Turkey, the research was conducted in Elazig on a sample of 100 subjects ( 55 boys and 45 girls), with the average age of 13.8 years. In Romania, the research was carried out in Galati on a sample of 94 subjects ( 50 boys and 44 girls), with an average age of 14.6. The age differences for similar classes are due to the fact that in Turkey children begin compulsory school at the age of 6 .

\section{Results and discussion}

Throughout childhood and adolescence, physical education in school provides an excellent opportunity to learn and practice the skills needed to improve physical strength and health status throughout life. These daily activities can include running, swimming, cycling and climbing as well as more structured sports and games. Early acquisition of basic skills makes it crucial for young people to practice and better understand the value of these activities in their later education or as adults at work or in their leisure time.

In order for physical education classes in school to achieve their goals in the formation and development of pupils, they must participate with pleasure, convinced that physical activity helps them maintain an optimal state of health, harmonious physical development, and personality development.

From the considerations mentioned above, the self-drafted questionnaire presented in Table 1 was conducted in order to find out how students appreciate the physical education classes, how attractive they are to them, and what are their views on improving the teacherstudent relationship.

Table 1. Content and comparative results between the two countries of the self-designed questionnaire

\begin{tabular}{|c|c|l|c|c|}
\hline Nr. & \multicolumn{1}{|c|}{ Question } & \multicolumn{1}{|c|}{ Answers } & Romania & Turkey \\
\hline \multirow{3}{*}{1.} & \multirow{2}{*}{$\begin{array}{l}\text { What do you think about physical education classes in the } \\
\text { school curriculum? }\end{array}$} & $\begin{array}{l}\text { There are too } \\
\text { many }\end{array}$ & $5.95 \%$ & $6.00 \%$ \\
\cline { 3 - 5 } & & There are too few & $90.48 \%$ & $93.00 \%$ \\
\cline { 3 - 5 } & & $\begin{array}{l}\text { There should not } \\
\text { be any }\end{array}$ & $3.57 \%$ & $1.00 \%$ \\
\hline \multirow{2}{*}{2.} & $\begin{array}{l}\text { Are you satisfied with the way your physical education } \\
\text { classes take place in your school? }\end{array}$ & Very satisfied & $39.29 \%$ & $34.00 \%$ \\
\cline { 3 - 5 } & & Satisfied & $41.67 \%$ & $54.00 \%$ \\
\cline { 3 - 5 } & & Dissatisfied & $10.71 \%$ & $9.00 \%$ \\
\cline { 3 - 5 } & & Very dissatisfied & $8.33 \%$ & $3.00 \%$ \\
\hline
\end{tabular}


Table 1.Continued

\begin{tabular}{|c|c|c|c|c|c|}
\hline \multirow{8}{*}{3.} & \multirow{8}{*}{$\begin{array}{l}\text { What is the main reason } \\
\text { that you attend the } \\
\text { physical education } \\
\text { class? }\end{array}$} & \multicolumn{2}{|c|}{ To maintain my physical strength } & $20.24 \%$ & $11.00 \%$ \\
\hline & & \multicolumn{2}{|c|}{ To improve my health } & $32.14 \%$ & $36.00 \%$ \\
\hline & & \multicolumn{2}{|c|}{ To meet with my peers } & $2.38 \%$ & $3.00 \%$ \\
\hline & & \multicolumn{2}{|c|}{ I like to socialize } & $1.19 \%$ & $10.00 \%$ \\
\hline & & \multicolumn{2}{|c|}{ I can relax/get rid of the stress } & $14.29 \%$ & $22.00 \%$ \\
\hline & & \multicolumn{2}{|c|}{ I improve my physical qualities } & $19.05 \%$ & $4.00 \%$ \\
\hline & & \multicolumn{2}{|c|}{ I like the competition } & $7.14 \%$ & $6.00 \%$ \\
\hline & & \multicolumn{2}{|c|}{ Other reason } & $3.57 \%$ & $8.00 \%$ \\
\hline \multirow{4}{*}{4.} & \multirow{4}{*}{$\begin{array}{l}\text { To what extent do you } \\
\text { agree with the practice } \\
\text { of physical activity? }\end{array}$} & \multicolumn{2}{|c|}{ To a very small extent } & $42.86 \%$ & $48.00 \%$ \\
\hline & & \multicolumn{2}{|c|}{ To a small extent } & $38.10 \%$ & $33.00 \%$ \\
\hline & & \multicolumn{2}{|c|}{ To a high extent } & $17.86 \%$ & $17.00 \%$ \\
\hline & & \multicolumn{2}{|c|}{ To a very high extent } & $1.18 \%$ & $2.00 \%$ \\
\hline \multirow{4}{*}{5.} & \multirow{4}{*}{$\begin{array}{l}\text { Have you received } \\
\text { rewards/sanctions during } \\
\text { your physical education } \\
\text { class? For what? }\end{array}$} & \multirow[t]{2}{*}{ Rewards } & yes & $54.76 \%$ & $43.00 \%$ \\
\hline & & & no & $45.24 \%$, & $57.00 \%$ \\
\hline & & \multirow[t]{2}{*}{ Sanctions } & yes & $10.71 \%$ & $25.00 \%$ \\
\hline & & & no & $89.29 \%$ & $75.00 \%$ \\
\hline \multirow{8}{*}{6.} & & \multicolumn{2}{|l|}{ Notes } & $91.46 \%$ & $19.64 \%$ \\
\hline & & \multicolumn{2}{|l|}{ Diplomas } & $15.85 \%$ & $14.29 \%$ \\
\hline & & \multicolumn{2}{|c|}{ Points } & $24.39 \%$ & $16.07 \%$ \\
\hline & What was & \multicolumn{2}{|c|}{ Verbal appraisals } & $35.37 \%$ & $62.86 \%$ \\
\hline & reward/sanction? & Medal & & $4.88 \%$ & $34.86 \%$ \\
\hline & & The decrea & in behaviour & $4.88 \%$ & $0.00 \%$ \\
\hline & & Eliminatio & & $4.88 \%$ & $12.50 \%$ \\
\hline & & Reprehens & & $7.32 \%$ & $22.07 \%$ \\
\hline & & Rewards & yes & $27,38 \%$ & $38,00 \%$ \\
\hline & Did you tell your parents & & no & $72,62 \%$ & $62,00 \%$ \\
\hline 7. & about the & Sanctions & yes & $57,14 \%$ & $81,66 \%$ \\
\hline & reward/sanction? & & no & $42,86 \%$ & $18,34 \%$ \\
\hline & & Initiative & & $32.14 \%$ & $16.00 \%$ \\
\hline & & Creativity & & $34.52 \%$ & $29.00 \%$ \\
\hline & What do you appreciate & Temperam & & $26.19 \%$ & $21.00 \%$ \\
\hline 8. & in a teacher? & The way $\mathrm{h}$ & lved & $60.71 \%$ & $60.00 \%$ \\
\hline & & The teache & tion skills & $34.52 \%$ & $39.00 \%$ \\
\hline & & Antipathy & ject & $11.90 \%$ & $12,67 \%$ \\
\hline & & Antipathy & cher & $14.29 \%$ & $7.00 \%$ \\
\hline 9. & order the causes of the & Indisciplin & & $20.24 \%$ & $30,09 \%$ \\
\hline & student-teacher conflict. & Evaluation & & $23.81 \%$ & $42,25 \%$ \\
\hline & & $\begin{array}{l}\text { The com } \\
\text { teacher }\end{array}$ & ethod of the & $29.76 \%$ & $7.00 \%$ \\
\hline & & The studen & anctioned) & $17.86 \%$ & $15.00 \%$ \\
\hline 10 & How are student-teacher & $\begin{array}{l}\text { Through } \\
\text { the teacher }\end{array}$ & ation between & $61.90 \%$ & $65.00 \%$ \\
\hline & conflicts solved? & $\begin{array}{l}\text { By prese } \\
\text { classroom }\end{array}$ & $\begin{array}{l}\text { uation to the } \\
\text { il }\end{array}$ & $3.57 \%$ & $6.00 \%$ \\
\hline & & By asking & e to the school & $16.67 \%$ & $14.00 \%$ \\
\hline
\end{tabular}

In the seventh grade, the school curriculum provides for 2 hours of physical education per week in Romania, and for similar classes in Turkey, only 1 hour of physical education per week. In the eighth grade, in both countries, it is only one hour per week. The number of physical education classes in the school curriculum is insufficient both in Romania and Turkey, this fact being confirmed by respondents' views on physical education classes that are very close and over $90 \%$ of the respondents consider that there are too few physical education classes, compared to those who consider them too many or would prefer not to 
have any at all. The answer confirms students' belief that physical education classes are beneficial to maintaining a good health and harmonious physical development.

Because students appreciate the physical education classes, I wanted to find out to what extent they are satisfied with the way in which physical education classes take place in the current format. The high number of students in Romania with a percentage of $41.67 \%$, and in Turkey with a percentage of $54.00 \%$, declared that they are satisfied and very satisfied about the way that physical education classes take place, confirming the answer to the previous question of increasing the number of physical education hours.

It was considered important for this research to know the extent to which participation in physical education is considered to be beneficial by pupils and, for that purpose, in question 3 of Table 1 we proposed a number of seven variants of answers and left a variant for one other reason than the seven proposed, to be mentioned by the respondent.

The main reason for the pupils in Romania and Turkey for attending the physical education class, according to the answers, is the improvement of the health status, response recorded in a percentage of $30 \%$. That is why some authors consider that the systematic practice of physical exercises has a multilateral influence on the physical and harmonious development of the organism [5].

The answers of the questioned pupils in Turkey are different compared to those in Romania, the differences being illustrated in Fig. 1. A percentage of $36.00 \%$ of the pupils in Turkey compared to $32.14 \%$ in Romania are participating in the physical education class to improve their health and only a percentage of $4.00 \%$ of the students are doing it to maintain their physical appearance compared to $19.05 \%$ in Romania. In a higher percentage of $22.00 \%$ compared to $14.29 \%$ for those in Romania, they mentioned participation in physical education as a way to relieve stress and relax.

On the other hand, the students in Turkey consider the physical education class as a relaxing, stress-free and socializing occasion, with a percentage of $22 \%$ in Turkey, compared to $14.29 \%$ in Romania.

Respondents in Romania considered other reasons, which are: doing sports is something normal, and during the physical education classes they learn new exercises and moves. Respondents from Turkey referred to reasons other than those mentioned in the questionnaire, namely: they are attracted to the games during the hours; love sports activities; they are attracted by the proposed social and educational activities in physical education classes; have the opportunity to play football; participation in physical education classes is beneficial to their mental state; consider sport to be normal and necessary. It should be noted that no response, both for the Romanian and Turkish students, mentioned participation in physical education classes as an obligation in the curriculum, which proves the important role of physical education and sports in school.

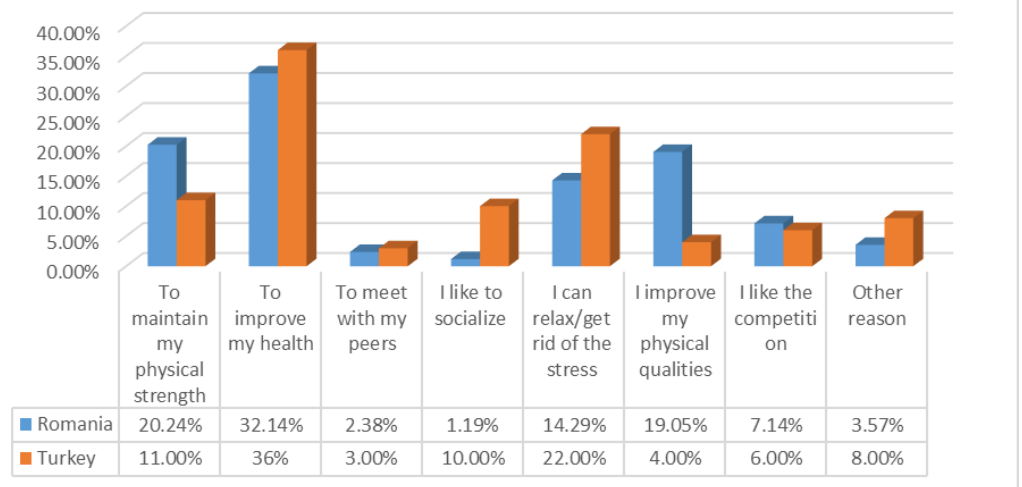

Fig 1 Comparing answers to the question "What is the main reason that you attend the physical education class?" 
The conscious practice of various physical sports activities by the gymnasium students creates the premise that movement and physical exercise will become a concern for them when they become adults.

Physical activity is any form of body movement that involves energy consumption. So physical activity is not synonymous with physical exercise, although it involves it.

Physical activities should take into account leisure activities, physical exercise, sports activities, various forms of walking (walking, cycling, climbing stairs), physical activity during school hours and household chores. The results of numerous research have shown that a lack of physical activity and a sedentary lifestyle pose a threat to health. That is why the next question addressed to the respondents followed the attitude manifested by them regarding physical activity. A relatively high percentage of respondents in both Romania and Turkey stated that they practice physical activity to a very small extent $(42.86 \%$ Romania and 48\% - Turkey), which shows that the only constant physical activity in their lives is the physical education class. This is also demonstrated by research in the past few years that has shown that there is a high percentage of children with a high degree of obesity due to lack of mainstream movement and unhealthy eating habits.

School regulations provide both rewards for students who achieve remarkable results in the physical education class and are distinguished by exemplary conduct and sanctions for students who violate regulations.

To find out to what extent the questioned pupils received rewards or sanctions in the physical education class, what the rewards or sanctions were, if they considered them to be deserved and if they were communicated to their parents, I asked them the following three questions, namely questions 5, 6 and 7 .

The answers to the question about the rewards and sanctions received show that Romanian students received more rewards (54.76\%) and fewer sanctions (10.71\%) compared to Turkish students, where $43.00 \%$ received rewards and $25.00 \%$ were sanctioned. The percentage differences between rewards and sanctions received by pupils at schools in both countries may be due both to students' behaviour during the physical education class and to school regulations that are not similar.

The reward/punishment system is a vicious system that, besides the positive influences it exerts on the student, it also contains negative aspects that may damage the student's status.

A reward is a form of praise in case of results that exceed the required level of demand, of results above the average of those usually obtained by regular students.

Research has shown that positive pedagogical methods (rewards, praises) have a stronger influence on pupils' outcomes and behaviour than negative pedagogical methods (sanctions, reprimands).

Students have a duty to learn for themselves and not for the fear of punishment or because they are attracted to the benefits of rewards because "We do not learn for school, we learn for life" [10].

In question 5, regarding the reward or sanction received, possible answers were suggested, but the free answer option was also provided if it was not a variant of the proposed ones. One response to the physical education sanction was the decrease in the behaviour grade. In this variation of an answer, it should be noted that in Turkey pupils do not receive grades for their behaviour in school, the deviations from the regulation being sanctioned by reprimand or removal from the hours.

The answers to the question as to what the reward or sanction was, were classified as: rewards - grades, diplomas, points, verbal appraisals, medals; sanctions - grades reduction, removal, reprimand. 
Students in Romania mentioned notes as a reward in a percentage of $91.46 \%$ as opposed to students in Turkey where only $19.64 \%$ mentioned grades as a reward.

In a significant percentage, in both countries, the students mentioned $35.37 \%$ verbal appraisals in Romania and $62.86 \%$ in Turkey as rewards for physical education classes. This demonstrates a different degree of appreciation of how recipients receive the rewards and sanctions that are made in the classroom's moral conscience.

It is necessary to apply sanctions only after a careful and serious investigation, taking into account the reasons and the student's personality, so that the punishment can have a positive, educational effect.

By positively motivating the way students act and behave, the teacher with pedagogical tact will strengthen their confidence in their own forces to overcome inevitable difficulties.

To act and behave correctly from a pedagogical point of view is to resort to pedagogical methods of a positive and negative nature (to correctly use rewards and punishments in the broad sense of their acceptance).

In order to evaluate students' attitudes towards rewards or sanctions, we asked for clarification if the rewards or sanctions were brought to their parents' attention.

Most of the sanctions received were not communicated to the parents as opposed to rewards that were communicated to the parents. The percentage of those who did not communicate the sanctions received to parents was higher for Romanian students, namely $72.62 \%$, compared to Turkey, $62.00 \%$. Rewards were communicated to parents in a percentage of $57.14 \%$ by the Romanian pupils and $81.66 \%$ by the pupils in Turkey.

By comparing the answers, one can conclude that Turkish students communicated more to their parents both the sanctions and the rewards received, being aware of the actions that they foresee.

The relationship between teacher and student in the physical education class contributes greatly to motivating students to practice physical activity and sports.

Asked what they appreciate in a teacher at question 8, the majority of the answers given by the students were about the way the teacher gets involved, respectively $60.71 \%$ (Romania) and $60.00 \%$ (Turkey), after which they mentioned, approximately in the same order, the communication skills of the teacher (34.52\%-Romania and 39,00\%-Turkey), creativity (34.52\%-Romania and 29.00\%-Turkey), and temperament (26.19\% in Romania and $21.00 \%$ in Turkey).

A significant proportion of pupils in Romania, respectively $32.14 \%$, appreciates the teacher's initiative, unlike the pupils in Turkey where only $16.00 \%$ gave this answer.

The physical education lesson depends largely on the teacher's involvement, the way he communicates with the pupils, the interaction with each student's personality and the achievement of a homogeneous group. These are the basic qualities of the teacher in order to make the lesson more effective and attractive to students.

There may be conflicts between teachers and pupils, which are based on various causes. I mentioned five possible causes that respondents would arrange in ascending order. The pupils in Romania considered the teacher's communication skills as the main reason for the conflict $(29.76 \%)$, followed by the evaluation $(23.81 \%)$, the indiscipline $(20.24 \%)$, the antipathy towards the teacher $(14.29 \%)$, and, in the last place the antipathy towards the subject (11.90\%). From their answers, it was concluded that in the physical education class the conflict arises because of a poor communication between the teacher and the student or because of the evaluation of the pupils on unknown criteria. They make the student have a negative attitude towards the physical education class and, even if he enjoys practicing physical activities, attending the lesson becomes a stress.

The pupils in Turkey mentioned the causes of the conflict as follows: the evaluation (42.25\%), followed by indiscipline $(30.09 \%)$, antipathy towards the object $(12.67 \%)$, the teacher's communication skills $(7.00 \%)$ and the antipathy towards the teacher $(7 \%)$. From 
the respondents' answers, we can see that assessment is a cause of conflict between students and teachers and it is generally due to subjectivism.

Solving the conflict between the teacher and the student means to first acknowledge the cause that generated the conflict and, starting from the idea that conflicts can be generated by the lack of communication or the indiscipline of the student, I proposed variants of answers for these situations. Both students in Romania $(69,05 \%)$ and those in Turkey $(63,00 \%)$, placed on the first place the teacher-student communication, followed by the sanctioning of the student (17,86\% in Romania and $15,00 \%$ in Turkey).

The next way to solve the conflict is considered by pupils in both countries to be the call of parents to school, $16.67 \%$ in Romania, and $11 \%$ in Turkey.

Solving the conflict between the teacher and the student in front of the teaching council is considered as a solution by only $61.90 \%$ of the respondents in Romania and $65.00 \%$ of the respondents in Turkey. The parties in the conflict have interdependent interests; conflicts are usually combinations of competitive and cooperative processes, and the course of the conflict will be determined by the nature of this combination. Conflict resolution can be achieved through interactive dialogue, bilateral feedback and mutual aid: the speaker must also listen and the listener must also communicate.

Ferriz et all [2] surveyed students' satisfaction in the Physical Education lesson (Spain) on a total of 405 boys and 453 girls aged between 15 to 21 and concluded that, in order to promote student satisfaction in PE, schools should promote educational environments that meet the students' needs for socialisation, competence, and autonomy by generating experiences in which students have fun and enjoy themselves.

Barney and Christenson [3] studied the attitudes of middle school students in physical education. The aim of this research was to determine the students' attitudes towards physical education. For this study, 227 midwestern middle school students from the United States were questioned, of which 28 students were interviewed regarding their attitudes towards physical education. It was found that middle school students tend to have positive attitudes towards physical education. Specifically, students considered physical education to be important for their general education and thought that the activities that they practice during the physical education classes are fun, considering physical education as being important in the day-to-day schooling of students.

The attitudes, motivations, and satisfaction of the gymnasium students vary from one country to another. This can be seen from the various research and their results. In order to achieve a high degree of satisfaction in the physical education class, the teacher has to orient his / her lesson objectives towards activities that please the pupils, stimulate them to participate in classes, and diversify the methods, exercises and sports materials. If a class of physical education is not appealing, the student attends the class but without the satisfaction of doing something useful and enjoyable.

\section{Conclusion}

After centralizing the data and analysing the answers, the opinions of the respondents, pupils in the 7th and 8th grades of the gymnasium cycle in Romania and Turkey, can be highlighted regarding the physical education classes in school.

It is worth noting that the use of the questionnaire with similar questions in the schools of the two countries with different cultural and religious traditions makes it difficult to compare the results.

The importance of the physical education class in the development and education of secondary school students is recognised in the curriculum of the two countries where the research was conducted. 
In both countries, physical education and sports require knowledge of all aspects associated with physical exercise, students' willingness to exercise and play sports, the enjoyment of physical activity, and the knowledge of the physical education's influence on their health.

From the answers obtained through the questionnaire used in the research, one can draw the following conclusions:

-the pupils in both countries consider the number of physical education classes in the curriculum to be insufficient, respectively $90.48 \%$ in Romania and $54.00 \%$ in Turkey;

- the way that the physical education classes take place is to the liking of the majority of students in both countries, respectively $41.67 \%$ in Romania and $88.00 \%$ in Turkey;

The percentage of those dissatisfied with how physical education classes take place is a signal for teachers to make the classes more attractive by practicing sports games adapted to the age and skills of the students that they work with during the class.

- the main reason for the participation of students in physical education is the maintenance of their physical appearance and optimal health status, for $32.14 \%$ of the students surveyed in Romania and $36.00 \%$ of the students surveyed in Turkey.

Starting from the principle that regular exercise and more diversified physical exercise are necessary in maintaining physical appearance and optimal health, it can be considered that the number of those who have opted for this type of response is quite reduced.

- considering students' attitudes towards exercise and practicing physical activities, the answers received have shown that they are mostly interested in exercise and physical activity.

The teacher, as an expert in the teaching-learning act, can make decisions about everything that happens in the process of learning.

Being faced with developing human beings, the teacher must show great sensitivity, attachment, and respect towards them. A concrete expression is love for children. This implies first and foremost respect and confidence in the internal capabilities that every child possesses, and the sincere desire for these opportunities to develop along the way.

Particularly important is the attitude of the teacher in his / her relationship with students. His/her authoritative position, somewhat despotic, is not indicated. It creates affective blockages. Students are afraid to ask questions. The authority of a teacher is not based on constraint, on fear, but on his professional competence, on his objectivity and respectable posture. He must be close to the pupils, indulgent (within the permissible limits, human) and encourage imagination.

-conflicts between teacher and student for students of both countries have as their main 2 causes the evaluation and communication skills of the teacher, with the indication that they are seen in different percentages by the respondents. In Romania, the teacher's communication skills is in the first position with $34.52 \%$ whereas in Turkey, a percentage of $39 \%$ indicated the same cause. The evaluation is seen in close proportions as the cause of the teacher-student conflict, namely $29.76 \%$ in Romania and indiscipline with $30.09 \%$ in Turkey.

-for solving the conflict between teacher and student, the teacher-student communication is seen by the vast majority of respondents as a solution, namely $61.90 \%$ in Romania and $65.00 \%$ in Turkey.

A conflict is a social phenomenon that occurs when two or more interacting actors pursue incompatible goals or have incompatible intentions or values.

Conflicts between teachers and students may also be triggered by poor communication. Most conflicts can be attributed to the misunderstanding or erroneous perception of intentions, feelings, needs, and actions. 


\section{References}

1. C. Alexandrache, Differentiated Education in The Service of Preventing / Reducing the School Conflict, Procedia - Social and Behavioral Sciences, 159 (2014), 433 - 436.

2. R Ferriz, A Sicilia, P Sáenz-Álvarez, Predicting satisfaction in physical education classes: A study based on self-determination theory, The Open Education Journal, 6 (2013), 1-7.

3. D Barney, R. Christenson, General attitudes of middle school students towards physical education. Asian Journal of Physical Education \& Recreation, 18, (2), (2012)., 24-32.

4. G. Mocanu, L. Nanu, The experimental curricula planning strategy, aimed at the combined motor abilities development during the 8th grade physical education lessons, The Annals of "Dunărea de Jos" University of Galati 2011, Physical Education and Sport Management, XV 1 (2011), 37

5. I. Siclovan, Teoria educaţiei fizice şi sportului Editura Stadion, (1972).

6. L.G. Talaghir, M. Ion-Ene, A study of the implementation of the new curriculum for physical education in the romanian primary education, 9th International Conference on Education. New Learning Technologies, (2017), 486-495,

7. L.G. Talaghir, V. Mîndrescu, Study regarding the use of physical exercise in order to prevent school-age children from being overweight, SHS Web of Conference, 37 (2017).

8. I. Nicola, Tratat de pedagogie şcolară, ARAMIS PRINT, (2002), 317

9. European Commission / EACEA / Eurydice, (2013), 29

10. Seneca, Epistulae Morales ad Lucilium, A Loeb Classical Library Edition; 1 (1917) 